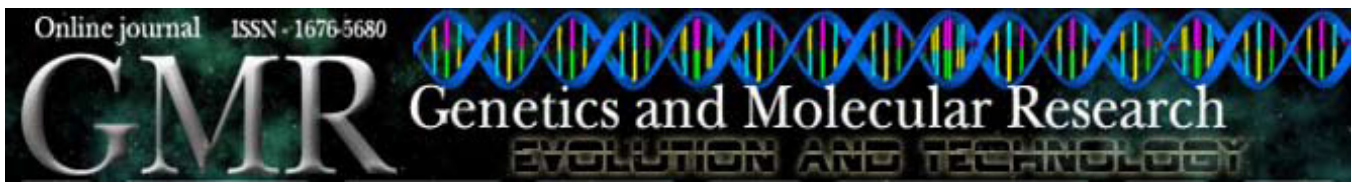

\title{
Does beekeeping reduce genetic variability in Melipona scutellaris (Apidae, Meliponini)?
}

\author{
G.A. Carvalho-Zilse ${ }^{1}$, M.F.F. Costa-Pinto ${ }^{2}$, C.G. Nunes-Silva ${ }^{3}$ \\ and W.E. Kerr ${ }^{4}$ \\ ${ }^{1}$ Grupo de Pesquisas em Abelhas (GPA/CPCA), \\ Instituto Nacional de Pesquisas da Amazônia, Manaus, AM, Brasil \\ ${ }^{2}$ Programa de Pós-Graduação em Genética, \\ Conservação e Biologia Evolutiva, Instituto Nacional de Pesquisas da Amazônia, \\ Manaus, AM, Brasil \\ ${ }^{3}$ Programa de Pós-Graduação em Biotecnologia, \\ Universidade Federal de Manaus, Manaus, AM, Brasil \\ ${ }^{4}$ Instituto de Genética e Bioquímica, \\ Universidade Federal de Uberlândia, Campus Umuarama, \\ Uberlândia, MG, Brasil
}

Corresponding author: G.A. Carvalho-Zilse

E-mail: gislene@inpa.gov.br

Genet. Mol. Res. 8 (2): 758-765 (2009)

Received December 12, 2008

Accepted January 26, 2009

Published June 30, 2009

\begin{abstract}
Many factors have contributed to reductions in wild populations of stingless bees, such as: deforestation, displacement and destruction of nests by honey gatherers, as well as use of insecticides and other agrochemicals. All of these can potentially affect the populational structure of native species. We analyzed genetic variability and populational structure of Melipona scutellaris, based on five microsatellite loci, using heterologous primers of M. bicolor. Samples were taken from 43 meliponaries distributed among 30 sites of four northeastern States of Brazil (Pernambuco, Alagoas, Sergipe, and Bahia). Thirty-one alleles were found to be well distributed among the populations, with sizes ranging from 85 to $146 \mathrm{bp}$. In general, there was a variable distribution and frequency of alleles among populations, with either exclusive and/or fixed alleles at some sites.
\end{abstract}


The population of Pernambuco was the most polymorphic, followed by Bahia, Alagoas and Sergipe. The heterozygosity was Ho $=0.36$ on average, much lower than what has been reported for M. bicolor (Ho $=0.65$ ). Most populations were not under Hardy-Weinberg equilibrium. We found a higher variation within rather than among populations, indicating no genetic structuring in those bees maintained in meliponaries. This apparent homogenization may be due to intense beekeeping activity, including exchange of genetic material among beekeepers. Based on our findings, we recommend more studies of meliponaries and of wild populations in order to help orient management and conservation of these native pollinators.

Key words: Stingless bees; Molecular markers; Single sequence repeats

\section{INTRODUCTION}

One of the first studies showing the importance of genetic diversity in natural populations of invertebrates was made by Saccheri et al. (1998). They observed imminent risk of extinction, especially among wild butterflies that have low levels of heterozygosity, such as Melitaea cinxia.

Studies of natural populations of invertebrates are needed to examine how isolation and population size affect genetic diversity. Moyle et al. (2003) pointed out invertebrates as a group needing more studies of population dynamics, both genetical and demographic, suggesting priorities for basic research on this topic.

The scientific community has sought to alert authorities and the public about endangered species. Hymenopteran populations, especially pollinators, can also diminish due to a loss of sexual alleles (Zayed et al., 2004). Loss of such bees negatively impact on cross-pollinated plants dependent on such pollinators for seed production (Zayed, 2004; Zayed and Packer, 2005; Hedrick et al., 2006).

Among the native pollinators, the stingless bees (Apidae, Meliponini; Roig-Alsina and Michener, 1993) are considered to be the principal pollinators of Brazilian plants (Kerr et al., 2001; Imperatriz-Fonseca et al., 2006). Many factors have contributed to reducing their populations, including: habitat loss, destruction of nests by honey hunters, spraying of insecticides and other agrochemicals. When populations are reduced due to such activities, a subsequent lack of allele variability at the sexual locus (complementary sex determiner gene - csd) results in diploid male production (Beye et al., 2003). Diploid males are killed soon after they emerge, as well as the queen that produced the eggs; after several generations, a local population may be lost (Kerr and Vencovsky, 1982; Carvalho et al., 1995; Kerr, 1996). The small number of wild stingless bee nests that still remain in forest fragments probably are under permanent pressure, exacerbated by the low sexual allele diversity (Kerr, 1997; Carvalho, 2001).

DNA analysis has become an important tool to understand the underlying mechanisms in bee population dynamics (Hoy, 1994). Although the $c s d$ gene has been isolated and in process of characterization to both Apis (Hasselmann and Beye, 2006) and Melipona genus (Nunes-Silva et al., 2006) so far there is no developed marker to monitor the 
genetic variability in bees for this locus. However among the diverse genetic markers available, microsatellites (single sequence repeats) have been indicated as the most informative to estimate populational parameters (Gao et al., 2002). The use of microsatellite markers in bees initiated with Estoup et al. (1993, 1995a,b) developing several microsatellite primers for honeybee (Apis mellifera) and bumblebee (Bombus terrestris). In these works, dinucleotide microsatellites $(\mathrm{CT})_{\mathrm{n}}$ were considered to be the most common within the bee group, differently from dipterans in which the dinucleotide $(\mathrm{GT})_{\mathrm{n}}$ is more abundant as a microsatellite motif (Estoup et al., 1993; Bonizzoni et al., 2000).

The first 25 microsatellite specific primers for the genus Melipona were designed by Peters et al. (1998) for M. bicolor. Among these, 18 loci were found to be polymorphic for this species. Several of these markers could be useful in other stingless bee species (Arias et al., 2006; Francisco et al., 2006).

Conservation, management and recovery of degraded populations of stingless bees require an approach that involves not only demographic and ecological factors, but also population genetics. Characterization of genetic structure and effective size population can be used to the effects of anthropic intervention (Kageyama, 1987; Nason and Hamrick, 1997).

Such genetic information is indispensable to increase the knowledge we need in order to successfully manage stingless bee colonies for honey production and pollination. Stingless bee beekeeping (meliponiculture) has great potential for supplementing family income in various regions of Brazil. Drumond (2004) considers meliponiculture a good alternative for sustainable activity in rural areas. Honey from these bees is widely appreciated as a source of food and medicine; frequently it provides complementary income for families in the Brazilian Northeast, where some beekeepers have up to 1500 stingless bee hives. In this region, the main species for beekeeping is Melipona scutellaris, considered one of the first bee species to be domesticated in the Americas (Kerr, 1996). We analyzed the genetic variability of M. scutellaris populations from four States of Brazil's northeast region, using microsatellite markers, in order to examine genetic structure.

\section{MATERIAL AND METHODS}

Adult individuals (workers) from Melipona scutellaris colonies were sampled from 43 meliponaries from 30 different sites (Figure 1) in four Brazilian northeastern States: nine in Pernambuco $(\mathrm{N}=14)$, five in Alagoas $(\mathrm{N}=8)$, five in Sergipe $(\mathrm{N}=7)$, and 11 in Bahia $(\mathrm{N}$ $=14)$. Bees were collected and conserved in absolute ethanol at $-20^{\circ} \mathrm{C}$. DNA was extracted following the protocol used by Paxton et al. (1996), using the salt-proteinase K extraction method. Five loci (Mbi 11, 13, 28, 88, and 213) were amplified using heterospecific primers developed for M. bicolor (Peters et al., 1998) in $20 \mu \mathrm{L}$ polymerase chain reaction mix, containing $1 \mathrm{X}$ reaction buffer (Pharmacia), 1 unit Taq DNA polymerase (Pharmacia), $2.5 \mathrm{pmol}$ of each primer marked with Cy5 fluorescence (Macromolecular Resources), $250 \mu \mathrm{M}$ dNTPs, $2 \mathrm{mM} \mathrm{MgCl}$ and $50 \mathrm{ng}$ DNA template. Amplifications were made using an MJ PTC thermal controller: $94^{\circ} \mathrm{C}$ for $3 \mathrm{~min}, 94^{\circ} \mathrm{C}$ for $35 \mathrm{~s}, 53^{\circ}$ to $57^{\circ} \mathrm{C}$ for $35 \mathrm{~s}, 72^{\circ} \mathrm{C}$ for $1 \mathrm{~min}(35 \mathrm{cycles})$ and a final amplification at $70^{\circ} \mathrm{C}$ for $10 \mathrm{~min}$. The amplified products were separated on $6 \%$ polyacrylamide gels (7.5 M urea - PAGE - Reprogel Pharmacia) in an ALF Express II sequencer (Amersham/Pharmacia/Biotech) at $1500 \mathrm{~V}, 25 \mathrm{~mA}, 40^{\circ} \mathrm{C}, 60 \mathrm{~W}$ for $200 \mathrm{~min}$. Internal markers of 200 and $250 \mathrm{bp}$, as well as 50 to $500 \mathrm{bp}$ external markers (Pharmacia) were used. Analyses 


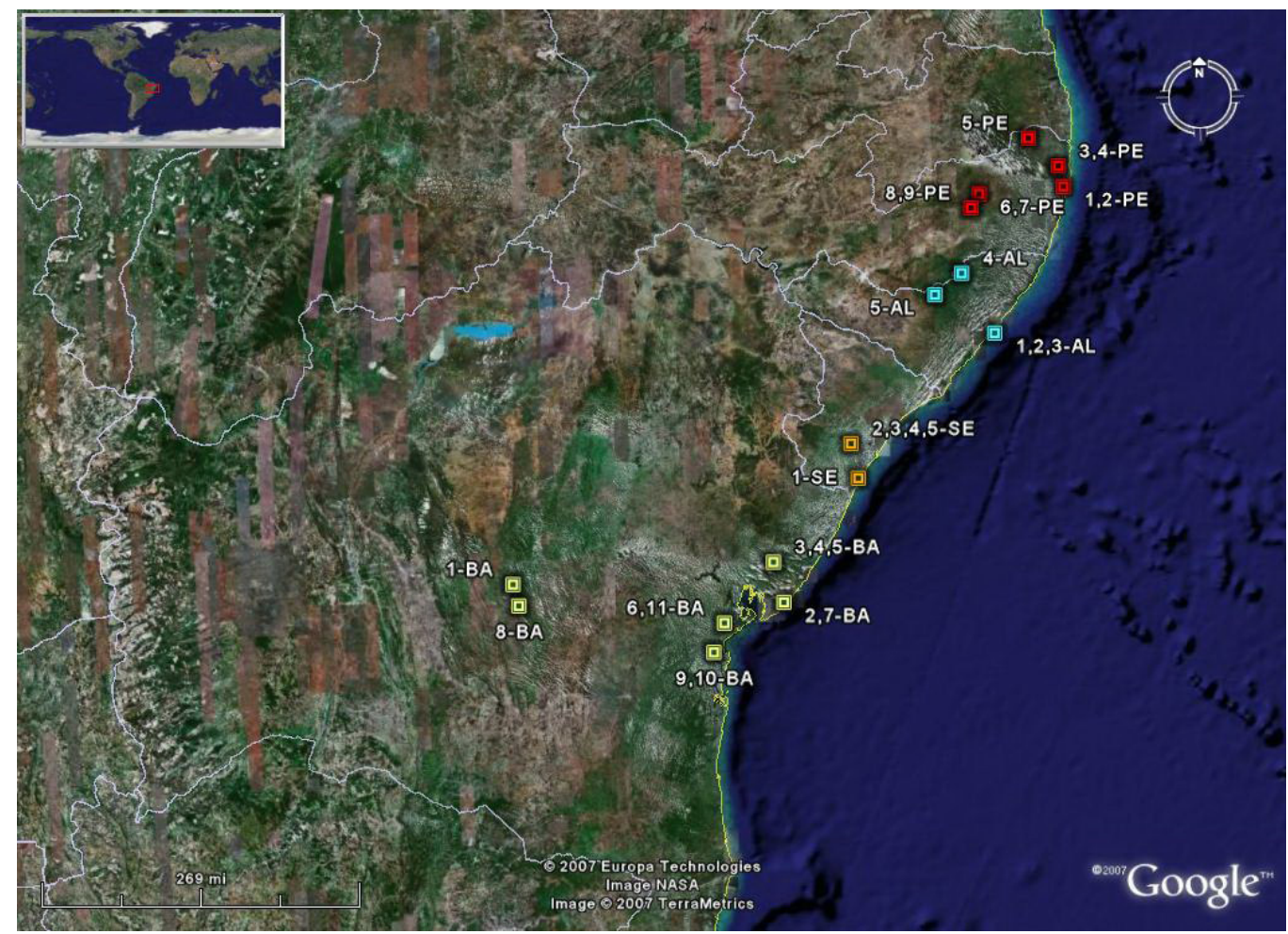

Figure 1. Map showing sites of Melipona scutellaris samples in four northeastern Brazilian States. Pernambuco: 1to 9-PE; Alagoas: 1- to 5-AL; Sergipe: 1- to 5-SE, and Bahia: 1- to 11-BA (Source: Google Earth, Version 2007).

were made with the AlleleLinks software version 1.00 (Pharmacia).

Statistical analyses were made with Arlequin (Schneider et al., 2000) to determine genetic variability, including $\mathrm{Ho}, \mathrm{He}$, and Hardy-Weinberg equilibrium. Population genetic structure was measured by calculating $\mathrm{F}_{\mathrm{ST}}$ and $\mathrm{F}_{\mathrm{IS}}$. This index, associated with the number of migrants per generation (Slatkin, 1995), was used to quantify the genetic flow among populations. The genetic diversity index within populations (Nei, 1972) provided a ratio of the variation in the number of different alleles among and within populations.

\section{RESULTS AND DISCUSSION}

Within the five amplified loci, we found 31 alleles, ranging from 85 to $146 \mathrm{bp}$ in size, well distributed among populations. In general, M. scutellaris had distinct distribution patterns and variable allelic frequencies among populations, with both exclusive and/ or fixed alleles depending on the collection site. The locus Mbi 28 (eight alleles) was the most polymorphic for this species, with the highest mean heterozygosity $(\mathrm{Ho}=0.91$; Table 1). 


\begin{tabular}{|c|c|c|c|c|c|c|c|c|}
\hline \multirow[t]{2}{*}{ Locus } & \multicolumn{2}{|c|}{ Pernambuco } & \multicolumn{2}{|c|}{ Alagoas } & \multicolumn{2}{|c|}{ Sergipe } & \multicolumn{2}{|c|}{ Bahia } \\
\hline & Но & $\mathrm{He}$ & Но & $\mathrm{He}$ & Но & $\mathrm{He}$ & Но & $\mathrm{He}$ \\
\hline Mbi 11 (2) & 0.07 & 0.07 & 0.13 & 0.13 & 0.14 & 0.14 & 0.00 & - \\
\hline Mbi 13 (5) & 0.31 & 0.67 & 0.00 & 0.53 & 0.00 & 0.44 & 0.18 & 0.44 \\
\hline Mbi 28 (8) & 0.92 & 0.79 & 0.86 & 0.89 & 1.00 & 0.88 & 0.86 & 0.85 \\
\hline Mbi 88 (6) & 0.21 & 0.30 & 0.13 & 0.34 & 0.29 & 0.65 & 0.29 & 0.71 \\
\hline Mbi 213 (10) & 0.69 & 0.87 & 0.50 & 0.85 & 0.14 & 0.76 & 0.50 & 0.81 \\
\hline Average & 0.44 & 0.54 & 0.32 & 0.55 & 0.31 & 0.57 & 0.36 & 0.56 \\
\hline
\end{tabular}

Only the Mbi 11 locus was found to be under Hardy-Weinberg equilibrium $(\mathrm{P}<0.05)$. The mean heterozysity observed for the five loci $(\mathrm{Ho}=0.36)$ was lower than expected $(\mathrm{He}$ $=0.56)$, which indicated that most of these loci are not at Hardy-Weinberg equilibrium $(\mathrm{P}<$ 0.05 ). This could be a consequence of small genetic populations, due to inbreeding caused by induced multiplication of colonies and selection for commercial characteristic values by stingless bee beekeepers, such as honey yields.

The mean heterozygosity observed for M. scutellaris was much lower than reported for M. bicolor (Peters et al., 1998). Possible explanations include: 1) heterospecific primers, 2) null alleles, and 3) M. bicolor can have up to five active physogastric queens in a colony. This would provide more genetic variability within the colony, as at least five different males contribute to alleles, if we consider a queen crossing with only one male (Velthuis et al., 2006).

When we compare the results with Apis data, our index is lower. Estoup et al. (1993) found Ho = 0.69 in Apis mellifera, De la Rúa et al. (2004) observed an average Ho of 0.45 for Apis mellifera iberica in Spain. Insuan et al. (2007) found an index of Ho $=0.71$ in Apis dorsata in Thailand. It is known that Apis queens can be fertilized by 15 to 17 males (Adams et al., 1977; Lobo and Kerr, 1993). This helps increase the number of microsatellite alleles (of paternal origin) among workers. Carvalho (2001), based on progeny analysis, reported that $5 \%$ of M. scutellaris queens mated with at least two males and $65 \%$ with only one, which could explain the low Ho index for this species.

If we compare M. scutellaris with other two species of Melipona in the Amazon region, the former also has a lower Ho index than M. compressipes but similar to M. seminigra (data not shown). The higher Ho of $M$. compressipes is probably due to the sampling of wild populations, compared to samples of $M$. scutellaris and M. seminigra, which were collected from meliponaries.

The variation was higher within (95.48\%) than among (4.52\%) populations of $M$. scutellaris. Analysis with the $\mathrm{F}_{\mathrm{ST}}$ test revealed no significant genetic structuring among populations of Pernambuco, Alagoas and Sergipe $(\mathrm{P}>0.05)$. Significant values of genetic structuring were found among populations of Pernambuco and Bahia, though with a very low index $\left(\mathrm{F}_{\mathrm{ST}}=0.08\right)$. A high inbreeding coefficient was found among these populations $\left(\mathrm{F}_{\mathrm{IS}}=0.32, \mathrm{P}=0.00\right)$, demonstrating an excess of homozygote individuals. This could be explained by the high number of migrants per generation among the states, which varies 
from 5.7 (between Pernambuco and Bahia) to 21.8 (between Alagoas and Sergipe), reaching an infinite number of effective migrants between Pernambuco and Alagoas. Wright (1969) says that the effect of populational differentiation can be minimized by one single migrant per generation. However, in these populations migration may not be natural since the populations are distant from each other. Melipona scutellaris, denominated regionally as Uruçu (indigenous name for big bee), is native to Atlantic forests, which years before used to cover huge areas on the Brazil coast. Nowadays only $7 \%$ remains of the original forest area, mainly in the Southeast and South regions of the country (Webventure, 2004). Observing the sampling sites and forest fragment distribution in the Northeast region, it is clear that there is a lack of continuous forest corridors among them, blocking gene flow among these populations. Some beekeepers have reported bee material exchange such as colonies, brood combs and queens among meliponaries in the same state but not so frequently among states. We believe that the genetic homogenization that we found among populations of M. scutellaris is artificial. The artificial "transit" of bee material has driven the populations to lower genetic variability. De la Rúa et al. (2004) found a similar for Apis mellifera iberica. They analyzed 48 colonies (1 individual/colonies) from 24 apiaries, and found high genetic diversity under no Hardy-Weinberg equilibrium at six single sequence repeat loci, indicating great genetic affinity among hives, especially since they ranged from Western Andalusian to North African populations. These authors attributed these findings to intense beekeeping activity. In contrast in $A$. dorsata (Insuan et al., 2007) and in A. cerana (Sihanuntavong et al., 1999) high genetic differentiation was found among populations, probably because of the short-range migration behavior in these bees. In Bombus ignitius, the migration distance is indicated by Shao et al. (2004) to be the main factor that drives genetic variation within and among populations. In B. ignitius, variation within populations is much higher than inter-population variation because of the capability of long distance migrations. Working with stingless bees, Brito (2005, apud Arias et al., 2006) suggests that in Partamona helleri and in P. mulata the low genetic variability and the moderate populational structuring may be due to one or more of three facts: 1) male migration among populations; 2) recent isolation resulting from rapid fragmentation of the savannas (Cerrado) and the Atlantic forest in Southern Brazil; 3) null alleles caused by the use of heterospecific primers.

Each population of M. scutellaris analyzed separately showed Pernambuco bees to be the most polymorphic, with $\mathrm{Ho}=0.44$ (molecular diversity index of $0.43 \pm 0.29$ ), followed by the Bahia population, with $\mathrm{Ho}=0.36$ (molecular diversity index of $0.52 \pm$ 0.36). Samples from Alagoas and Sergipe gave the lowest numbers of heterozygotes, with Ho $=0.32\left(\mathrm{~F}_{\mathrm{IS}}=0.42\right)$ and $\mathrm{Ho}=0.31\left(\mathrm{~F}_{\mathrm{IS}}=0.48\right)$, respectively, indicating a high degree of heterozygote deficiency. However, these two sites presented the highest indexes of molecular diversity $(0.46 \pm 0.31$ for Alagoas and $0.50 \pm 0.33$ for Sergipe) showing that though there were few heterozygotes, these populations contain higher allele diversity within the loci. Such results may be due to the intense beekeeping activity in Pernambuco and Bahia compared to Alagoas and Sergipe. Summarizing, the management techniques and colony selections (e.g., selection of hives for higher honey yields) seem to be collaborating to increase some allele frequencies and diminishing others within populations. However, there is a need for more studies to monitor populations under beekeeping compared to wild populations in order to help orient management and conservation programs of these native pollinators. 


\section{ACKNOWLEDGMENTS}

Research supported by CNPq, CAPES and FAPEAM, for which we are grateful. We thank Prof. MSc. R.M.O. Alves and all beekeepers who provided bee samples. The three first authors are especially pleased to have worked under Prof. Kerr's coordination and we would like to dedicate this article to him in celebration of his life dedicated to bee research. A person always committed to educate and to bring knowledge to all Brazilians, from universities and science academies to rural communities and indigenous tribes. A living example for the new generation of bee scientists.

\section{REFERENCES}

Adams J, Rothman ED, Kerr WE and Paulino ZL (1977). Estimation of the number of sex alleles and queen matings from diploid male frequencies in a population of Apis mellifera. Genetics 86: 583-596.

Arias MC, Brito RM, Francisco FO, Moretto G, et al. (2006). Molecular markers as a tool for population and evolutionary studies of stingless bees. Apidologie 37: 259-274.

Beye M, Hasselmann M, Fondrk MK, Page RE, et al. (2003). The gene csd is the primary signal for sexual development in the honeybee and encodes an SR-type protein. Cell 114: 419-429.

Bonizzoni M, Malacrida AR, Guglielmino CR, Gomulski LM, et al. (2000). Microsatellite polymorphism in the Mediterranean fruit fly, Ceratitis capitata. Insect Mol. Biol. 9: 251-261.

Carvalho GA (2001). The number of sex alleles (CSD) in a bee population and its practical importance (Hymenoptera: Apidae). J. Hymenoptera Res. 10: 10-15.

Carvalho GA, Kerr WE and Nascimento VA (1995). Sex determination in bees. XXXIII. Decrease of xo hetero-alleles in a finite population of Melipona scutellaris (Apidae, Meliponinae). Braz. J. Genet. 18: 13-16.

De la Rúa P, Hernández-García P, Pedersen BV, Galián J, et al. (2004). Molecular diversity of honeybee Apis mellifera iberica L. (Himenoptera: Apidae) from Western Andalusia. Arch. Zootec. 53: 195-203.

Drumond P (2004). Abelhas indígenas sem ferrão. Embrapa/CPAFAC: Acre, 2004. Available at [http://www.cpafac. embrapa.br/chefias/cna/artigos/abelhas.htm]. Accessed July 5, 2007.

Estoup A, Solignac M, Harry M and Cornuet JM (1993). Characterization of (GT)n and (CT)n microsatellites in two insect species: Apis mellifera and Bombus terrestris. Nucleic Acids Res. 21: 1427-1431.

Estoup A, Scholl A, Pouvreau A and Solignac M (1995a). Monoandry and polyandry in bumble bees (Hymenoptera; Bombinae) as evidenced by highly variable microsatellites. Mol. Ecol. 4: 89-93.

Estoup A, Tailliez C, Cornuet JM and Solignac M (1995b). Size homoplasy and mutational processes of interrupted microsatellites in two bee species, Apis mellifera and Bombus terrestris (Apidae). Mol. Biol. Evol. 12: 1074-1084.

Francisco FO, Brito RM and Arias MC (2006). Alelle number and heterozygosity for microsatellite loci in different stingless bee species (Hymenoptera: Apidae, Meliponini). Neotrop. Entomol. 35: 638-643.

Gao LZ, Schaal BA, Zhang CH, Jia JZ, et al. (2002). Assessment of population genetic structure in common wild rice Oryza rufipogon Griff. using microsatellite and allozyme markers. Theor. Appl. Genet. 106: 173-180.

Hasselmann M and Beye M (2006). Pronounced differences of recombination activity at the sex determination locus of the honeybee, a locus under strong balancing selection. Genetics 174: 1469-1480.

Hedrick PW, Gadau J and Page RE Jr (2006). Genetic sex determination and extinction. Trends Ecol. Evol. 21: 55-57.

Hoy MA (1994). Insect Molecular Genetics: an Introduction to Principles and Applications. Academic Press, San Diego.

Imperatriz-Fonseca VL, Saraiva AM and De Jong D (2006). Bees as Pollinators in Brazil: Assessing the Status and Suggesting Best Practices. Holos, Ribeirão Preto.

Insuan S, Deowanish S, Klinbunga S, Sittipraneed S, et al. (2007). Genetic differentiation of the giant honey bee (Apis dorsata) in Thailand analyzed by mitochondrial genes and microsatellites. Biochem. Genet. 45: 345-361.

Kageyama PY (1987). Conservação in situ de recursos genéticos de plantas. IPEF 35: 7-37.

Kerr WE (1996). Tiuba: a Abelha do Maranhão. EDUFMA, São Luís.

Kerr WE (1997). Sex determination in honey bees (Apinae and Meliponinae) and its consequences. Braz. J. Genet. 20: 601-611.

Kerr WE and Vencovsky R (1982). Melhoramento genético em abelhas I. Efeito de número de colônias sobre o melhoramento. Braz. J. Genet. 5: 279-285.

Kerr WE, Carvalho GA, Da Silva AC and Assis MG (2001). Aspectos poucos mencionados da biodiversidade amazônica. 
Parc. Estrat. 12: 20-41.

Lobo JA and Kerr WE (1993). Estimation of the number of matings in Apis mellifera; extensions of the model and comparison of different estimates. Ethol. Ecol. Evol. 5: 237-345.

Moyle L, Stinchcombe J, Hudgens B and Morris W (2003). Conservation genetics in the recovery of endangered animal species: a review of U.S. endangered species recovery plans (1977-1998). Anim. Biodiv. Conserv. 26: 85-95.

Nason JD and Hamrick JL (1997). Reproductive and genetic consequences of forest fragmentation: two case studies of Neotropical canopy trees. J. Heredity 88: 264-276.

Nei M (1972). Genetic distance between populations. Am. Nat. 106: 283-292.

Nunes-Silva CG, Astolfi-Filho S, Kerr WE and Carvalho-Zilse GA (2006). Perfil de ESTs em Larvas de Melipona compressipes (Apidae, Meliponini). In: Anais do VII Encontro sobre Abelhas, Ribeirão Preto.

Paxton RJ, Thoren PA, Tengo J, Estoup A, et al. (1996). Mating structure and nestmate relatedness in a communal bee, Andrena jacobi (Hymenoptera, Andrenidae), using microsatellites. Mol. Ecol. 5: 511-519.

Peters JM, Queller DC, Fonseca VL and Strassmann JE (1998). Microsatellite loci for stringless bees. Mol. Ecol. 7: 784-787.

Roig-Alsina A and Michener CD (1993). Studies on the phylogeny and classification of long-tongued bees (Hymenoptera, Apoidea). Univ. Kansas Sci. Bull. 55: 123-173.

Saccheri I, Kuussaar M, Kankare M, Vikman P, et al. (1998). Inbreeding and extinction in a butterfly metapopulation. Nature 392: 491-494.

Schneider S, Roessli D and Excoffier L (2000). Arlequin Version 2000: A Software for Population Genetic Data Analysis. Genetics and Biometry Laboratory, University of Geneva, Geneva.

Shao ZY, Mao HX, Fu WJ, Ono M, et al. (2004). Genetic structure of Asian populations of Bombus ignitus (Hymenoptera: Apidae). J. Hered. 95: 46-52.

Sihanuntavong D, Sittipraneed S and Klinbunga S (1999). Mitochondrial DNA diversity and population structure of the honey bee (Apis cerana) in Thailand. J. Apic. Res. 38: 211-219.

Slatkin M (1995). A measure of population subdivision based on microsatellite allele frequencies. Genetics 139: 457-462.

Velthuis HHW, Vries H and Imperatriz-Fonseca VL (2006). The polygyny of Melipona bicolor: scramble competition among queens. Apidologie 37: 222-239.

Webventure (2004). Hoje é o Dia Nacional da Mata Atlântica 27/05/04 - 10h07. Available at [http://www.webventure. com.br/offroad/conteudo/noticias/index/id/12122?pag=1 ]. Accessed July 8, 2007.

Wright S (1969). Evolution and the Genetics of Populations. Vol. 2. Theory of Gene Frequencies. The University of Chicago Press, Chicago.

Zayed A (2004). Effective population size in Hymenoptera with complementary sex determination. Heredity 93: 627-630.

Zayed A and Packer L (2005). Complementary sex determination substantially increases extinction proneness of haplodiploid populations. Proc. Natl. Acad. Sci. U. S. A. 102: 10742-10746.

Zayed A, Roubik DW and Packer L (2004). Use of diploid male frequency data as an indicator of pollinator decline. Proc. Biol. Sci. 271 (Suppl 3): S9-S12. 